\title{
Carbon source and sink analysis of rhizosphere micro-ecosystem of Calamagrostis angustifolia in Xiaoxing'anling in Northeast China
}

\author{
Xiuping Cai ${ }^{1, a}$, JiGuang $\mathrm{Li}^{2,4, b}$, Qishuo Wang ${ }^{3, c}$, Hui Sun ${ }^{5, d}$, Wei Xie ${ }^{6}$, Zhenhua \\ Liu $^{6}$, Weiming $\operatorname{Tan}^{6}$ \\ ${ }^{1}$ Jiangsu Food \& Pharmaceutical Science College, Huai'an, Jiangsu, China. \\ 2 College of Life Sciences and Technology, Mudanjiang Normal University, Mudanjiang 157012, Ch \\ ina; \\ ${ }^{3}$ Huaian Reasearch Center, Institute of Hydrobiology, Chinese Academy of Sciences, Huai'an, \\ Jiangsu, China \\ ${ }^{4} \mathrm{~S}$ tate Key Laboratory of Urban Water Resource and Environment, Harbin Institute of Technology, \\ Harbin, Heilongjiang, 150090, China \\ ${ }^{5}$ School of Environmental Science and Engineering, Hubei Key Laboratory of Mine Environmental \\ ${ }^{6}$ Department of Physics and Mathematics, Wuzhou University,Wuzhou,Guangxi 543002,China \\ a xiupingcai2008@126.com , blijiguangljg@163.com, 'c10396648@qq.com dsunhui0709@163.com
}

Keywords: Carbon fixation and soil carbon accumulation method;The carbon source/sink; NET ecosystem exchange method

\begin{abstract}
Paper selected paludification meadows lobular chapter of the dominant species as the research object, analyses the Calamagrostis angustifolia rhizospheric microecosystem carbon source estimation method and its intensity throughout the growing season Calamagrostis angustifolia rhizospheric microecosystems characterized by carbon sinks, to plant carbon fixation and soil carbon accumulation method, column experiment and the small room in the amount of carbon accumulation in the growth season, and its net ecosystem exchange method to estimate the columnar experiment of carbon accumulation in the growing season In this paper, using the two methods respectively by means of simulation experiment to seasonal change lobular chapter ecosystem was studied, and estimate the Calamagrostis angustifolia rhizospheric carbon source sink relationship and its intensity.
\end{abstract}

\section{Introduction}

The global environment change is human beings are facing with the important and urgent environmental problem[1,2]s: in natural and human action double drive, the surface of the earth element biogeochemical process and its environmental effect is the current global change research in the area of the important content. In order to estimate and forecast geochemical cycle of change and to the global life support system influence, since the $1970 \mathrm{~s}$ on the ecological system of the nitrogen cycle extensive and in-depth research, and in the process of this a series of ecological environment effect[3-5]. Wetland biogeochemical process is refers to the carbon, hydrogen (water), oxygen, nitrogen, phosphorus and sulfur and various essential elements in the wetland soil and plant all kinds of migration between transformation and energy exchange process (J.R. Ethiopia, 1989). Chemical process including nitrogen, phosphorus and other nutrients in the wetland system of flow and transformation, Wetland in heavy metals and other organic inorganic pollutants absorption, so close, transformation and enrichment, etc[6-8]. This paper discussed the typical types of wetland ecosystem of litter decomposition dynamics and organic matter composition change, system illustrate different microenvironment component content and the influence of the residual rate of organic matter, and explore the function of wetland ecosystem, abundant wetland ecology research, in order to further explore the formation and development of wetland theory provides the basic data support, has important significance for wetland protection and management. 


\section{Sample selection and credit rating}

The soil sample collection. Soil sample collection in the sample set, dig $1 \mathrm{~m}$ multiply one $\mathrm{m}$ square pit, according to the structure characteristics of soil, respectively acquisition different levels of soil, press $0 \sim 10 \mathrm{~cm}, 10$ to $30 \mathrm{~cm}, 30-\mathrm{cm}$ and $-90 \mathrm{~cm}$ four layer for sampling, for convenience, the paper described the topsoil and called A and B, C layer. Choose a total of three sample, respectively in the same way after earth mixed. According to the characteristics of the soil profile, $0 \sim 30 \mathrm{~cm}$ for humus layer, $30 \sim$ sixty $\mathrm{cm}$ for glei, then gradually transition to the parent material, the meadow bog soil.

Vegetation sample collection. Vegetation sample collection and soil sample collection synchronously. Set in the sample area, every month for acquisition time, divided into $1 \mathrm{~m}$ multiply one $\mathrm{m}$ sample region and $9000 \mathrm{~cm} 3$ cube take root zone. The samples were collected in different plants of different components (Uranus carex mainly is the leaves, leaf sheath and root sheath, root and low fall), in sealed plastic bags, back to the laboratory immediately, classification, and then say fresh weight, in $105{ }^{\circ} \mathrm{C}$ after filming under twenty minutes, and in $80{ }^{\circ} \mathrm{C}$ under constant temperature drying to constant weight, weighing, load in the belt

\section{The nutrient elements distribution and dynamic change}

The soil nitrogen in succession in different periods of the content is not only significant difference (Table 1), and existing form also have very big difference. Plants use nitrogen form basically has two kinds, namely nitrate and ammonium salt. Nitrate is easy to move, easy to loss, often reduced; And ammonium salt are relatively stable, very easy to form and is not easy to loss. Some plants can secrete inhibiting nitrogen microbial activity of chemicals in the soil will increase ratio of ammonium salt.

The effect of nitrogen in synthesis of amino acid, protein, nucleic acid and phospholipid, chlorophyll, enzymes, vitamin and so on, to promote the growth of plant nutrition, delay aging, improve photosynthetic efficiency, improve plant fruit quality and yield. Nitrogen is the most abundant in the atmosphere of the content of elements, but also the land ecological system plant productivity element of the restrictions. In the natural ecological system, the soil nitrogen mainly comes from the biological nitrogen and with precipitation into the soil, the soil moisture of the nitrogen and high temperature to nitrogen fixed. In the long process under the action of soil, soil nitrogen formed under the condition of particular ecological balance.

Table 1 Spatial and temporal distribution change of Total Nitrogen content in soil

\begin{tabular}{cccccc}
\hline Time & $2012 / 5$ & $2012 / 6$ & $2012 / 7$ & $2012 / 8$ & $2012 / 9$ \\
\hline All N (mg/kg) & 13000 & 5000 & 6000 & 12000 & 1000 \\
A N (mg/kg) & 4000 & 11000 & 10000 & 9000 & 8000 \\
B N (mg/kg) & 5000 & 4000 & 3000 & 3000 & 2000 \\
C N (mg/kg) & 7000 & 1000 & 2000 & 3000 & 0 \\
\hline
\end{tabular}

In the metabolism process, phosphorus to transfer, storage and release energy, promote the carbohydrate transportation, and improve the protein content, promote root development and flower bud formation, improve the resistance. Most of the soil phosphorus is delayed sex state is, so the soil total phosphorus content and can be used as the indicator of soil p supply, total phosphorus high does not mean that $\mathrm{p}$ supply enough, and total phosphorus content was lower than a monohydrate at ordinary times, but could mean $\mathrm{p}$ in short supply.

As shown in Table 2: from the profile and season look, surface total phosphorus in June, July began to decline to minimum value, surface is $149.58 \mathrm{mg} / \mathrm{kg}$, in August, maximum surface is $1566.02 \mathrm{mg} / \mathrm{kg}$ and then fell. 
Table 2 Spatial and temporal distribution change of total Phosphorus content in soil

\begin{tabular}{cccccc}
\hline Time & $2012 / 5$ & $2012 / 6$ & $2012 / 7$ & $2012 / 8$ & $2012 / 9$ \\
\hline All P(mg/kg) & 1600 & 400 & 200 & 1600 & 1000 \\
A P $(\mathrm{mg} / \mathrm{kg})$ & 800 & 1400 & 1200 & 1000 & 15000 \\
B P(mg/kg) & 1100 & 1000 & 1100 & 1000 & 1200 \\
C P(mg/kg) & 1300 & 1000 & 800 & 1000 & 900 \\
\hline
\end{tabular}

Potassium is one of the three elements of plant nutrition, the plants play important roles in the body, the effect of potassium, maintain cell plasmatic colloid system and vacuole buffer system, promote the organization mature, promote carbohydrate synthesis, which is beneficial to the growth of branches, and improve the bold fruit quality and resistance to hide sex. Mainly potassium ions in cells, it is not a cell composition, it is essential plant only a price, also be a plant cation in the highest content of metal elements, mainly focus on the growth of the most active part. It is many enzyme activator, regulate the plant transpiration. Plant potassium deficiency, plant easily dehydrate wilting, and at the same time, potassium can improve the resistance of plants, and promote the new photosynthetic product transportation, but also to storage material operation may also be affected(Fig. 1).

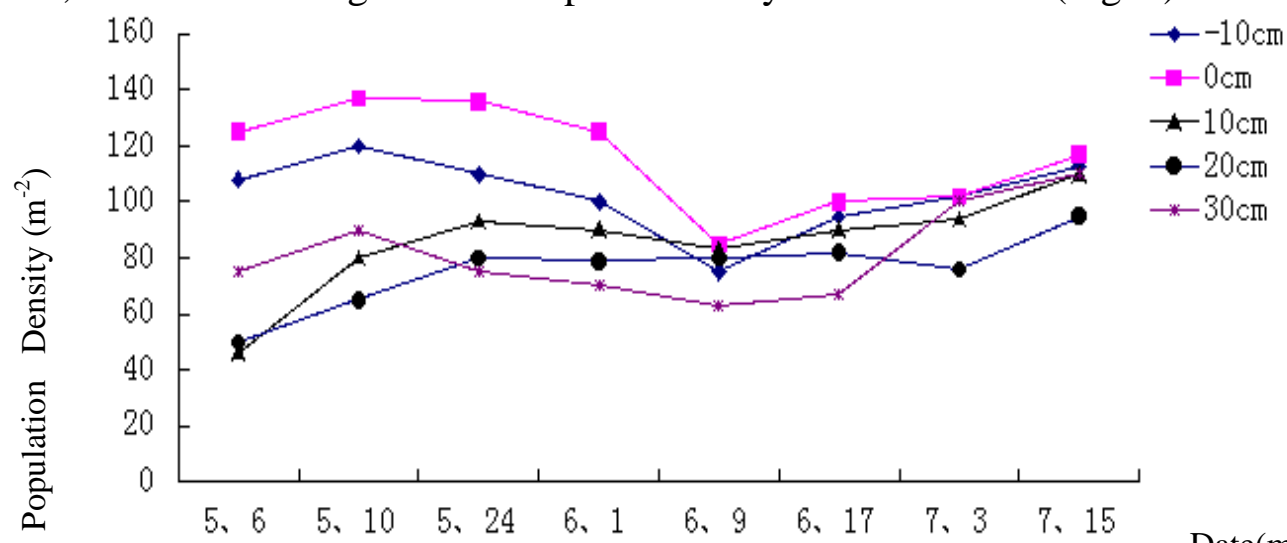

Fig. 1 Dynamic population density of Calamogrostis angustifolia - Car

Date(month、 day) at different water levels

From soil profile change (Table 3), with the deepening of profile, potassium content is more and more big. In the surface soil potassium content in May is a bit low, $7559.44 \mathrm{mg} / \mathrm{kg}$ in July, 10986.12 $\mathrm{mg} / \mathrm{kg}$, dropped to 6778.54 in September. A layer of change and the change of surface layer, on the other hand, may surface is high, A layer is as high as $12488.24 \mathrm{mg} / \mathrm{kg}$, in June, the lowest 7482.18 $\mathrm{mg} / \mathrm{kg}$, after July and August to rise to the decline in September.

Table 3 Spatial and temporal distribution change of total Kalium content in soil

\begin{tabular}{cccccc}
\hline Time & $2012 / 5$ & $2012 / 6$ & $2012 / 7$ & $2012 / 8$ & $2012 / 9$ \\
\hline All K $(\mathrm{mg} / \mathrm{kg})$ & 6500 & 7500 & 800 & 7500 & 5100 \\
A K $(\mathrm{mg} / \mathrm{kg})$ & 12000 & 6000 & 6100 & 7500 & 7000 \\
B K $(\mathrm{mg} / \mathrm{kg})$ & 12000 & 11550 & 1100 & 11600 & 12000 \\
C K $(\mathrm{mg} / \mathrm{kg})$ & 10000 & 17500 & 17000 & 15900 & 16000 \\
\hline
\end{tabular}

\section{Conclusion}

Total potassium and total nitrogen is a significant negative correlation; Quick nitrogen and total nitrogen, total potassium significant positive correlation; Soluble calcium and total nitrogen, total potassium, grain nitrogen are significantly positive correlation[9]. Soluble magnesium and total phosphorus are significantly positive correlation; All calcium and total nitrogen, soluble magnesium is a significant positive correlation[10,11]. Organic matter and total nitrogen, quick nitrogen, soluble calcium are significantly positive correlation, and total potassium significant negative correlation; And 
all the calcium is a significant positive correlation; $\mathrm{PH}$ value and total phosphorus a significant negative correlation; Nitrate nitrogen and effective magnesium, effective zinc a significant negative correlation, and all the magnesium, copper, manganese effective all significant positive correlation, and all the zinc is a significant negative correlation, and all the copper, effective copper is a significant positive correlation.

This study reveals the swampy valleys ho carex soil nutrient elements in the season and space change rule of each element and the interaction, the associated characteristics for the interpretation of cambia mountain valleys swamp wetland vegetation community succession, as well as the wetland biological diversity analysis lays a foundation, which need to be further studied.

\section{Acknowledgments}

This work was financially supported by monitoring and remediation technology of antibiotics in aquatic water, HAS2013038.

\section{References}

[1] Pitelka IF. Energy allocation in annual and perennial Lupines (Lupinus; Leguminosae) [J]. Ecology. 2012,93:1055 1065.

[2] Yu Kongjian. The reasonable countermeasure of urban wetland utlization[J]. Information of China Construction, 2005, 3 (9) : 9-12.

[3] Sims P L. The structure and function of ten Western Notth American grasslands turnover and efficiencies of energy Capture and water use[J]. J. ECOl.2008，96:573—59

[4] He Yan, Deng Wei, Zhang Guang xin, Pan Ji hua. Study on the spatial variability of water nitrogen and phosphorus in the zhalong wetland[J].Research of Environmental Sciences, 2005, 2(18):51-56.

[5] Duan Chang qun. Environment biology[M].Science Press, 2004: 102.

[6] Gao Ping. Microbiology[M].Higher Education Press, 2000，11（5）: 311-312.

[7] Zhang Ying, Huang Lin nan, Ao Jing. Study on the contributions of microorganisms in nitrogen cycle of wetlands[J].Water Resource Protection, 2004, 9: 61-69.

[8] Odorico P D, Laio F, et al. Hydrologic controls on soil carbon and nitrogen cycles; I modeling scheme[J]. Advances in Water Resources,2003,26:45-58.

[9] Jiguang Li, Yibin Ren, Di Guan, Nanqi Ren. Effect of Chlorination Conditions on Amount of THMs[J]. Advanced Materials Research, 2011, 420: 2294-2297

[10] Jiguang Li, Yibin Ren, Di Guan, Nanqi Ren. Ecological Safety Analysis and Statistics Measures of Wuyiling Wetland in Yichun in Northeast China[J]. Advanced Materials Research, 2011, 419: 2298-2301

[11] Jiguang Li, Yibin Ren, Nanqi Ren. Influence of Microorganisms on Nitrogen Cycle of Urban Wetland in Northeast China[J]. ICEEP 2012, 521: 5055-5058 